\title{
Hidden Orders on Euronext: Nothing is quite as it seems...
}

\author{
C. D'Hondt ${ }^{a}$ and R. De Winne ${ }^{b}$ and A. François-Heude ${ }^{c}$ \\ ${ }^{a}$ FUCaM and University of Perpignan, ${ }^{b}$ FUCaM, ${ }^{c}$ University of Perpignan
}

First version: November 2002

This version: September 2003

\begin{abstract}
This paper is devoted to hidden order submission on Euronext, especially for the stocks belonging to the CAC40 index during the three last months of 2002. The goal is twofold. On the one hand, we investigate the impact of hidden order use on market depth and pretrade transparency. Thanks to the order book rebuilding, we find that more than one third of the volume available at the 5 best limits is not visible on the market screens. We also show that hidden depth at the top of the order book varies a lot all along the continuous session while displayed depth is quite stable. Furthermore, we highlight that short-term volatility affects significantly hidden depth magnitude. On the other hand, we compare hidden order placement with usual order submission. We analyze order aggressiveness and interactions between the order flow and the order book. Our results suggest that hidden order traders are mainly liquidity suppliers who focus especially on the 5 best limits of the order book. They also appear to focus on a given market side at a point in time and are less concerned than usual order traders with what happens on the opposite market side. Finally, we find evidence of splitting strategies for hidden orders placed below the best bid or ask price.
\end{abstract}

JEL Classifications : G14, G10

Keywords : Hidden orders, Market depth, Order aggressiveness, Transparency.

\section{Acknowledgements}

The authors are grateful to Euronext for providing the data. They also wish to thank C. Bisière, F. Declerck, C. Majois and I. Platten for suggestions and remarks. Comments are welcome.

\section{Mailing Address}

FUCaM-Catholic University of Mons, Department of Finance, chaussée de Binche 151, B7000 Mons, BELGIUM, tel. +32.65.323324, fax +32.65.323223, e-mail : catherine.dhondt@fucam.ac.be. 


\section{Introduction}

In order-driven markets, liquidity suppliers expose limit orders to attract liquidity demanders. The order exposure risk is thus straight related to the market transparency level. Indeed, the information diffusion in real time affects the process of information inference and the revision of beliefs. Order exposure can be harmful if it reveals the traders' motives or the price impact of futures trades or valuable free trading options. In a transparent market, some parasitic traders may try to profit from disclosed limit orders at the expense of liquidity suppliers. Front-runners try to infer securities values from the displayed order flow to get profit. Quote-matchers tend to benefit from implicit trading options. Today, many stock exchanges or ECNs rely on limit orders for liquidity supply and partially diffuse in real time the order book. To remain competitive, many transparent trading systems allow market participants to control their exposure risk by specifying a partial display of their orders. In this context, hidden orders permit traders to disclose only a part of the total quantity they want to buy or sell. The total order size is registered in the order book but only the disclosed quantity is displayed on the market screens.

A few number of previous studies provide empirical investigations of hidden order use. Harris (1996) examines data for 300 stocks traded on the Paris Bourse and shows that $74 \%$ of orders are not fully disclosed when the remaining size is larger than FF500,000. His findings suggest that traders expose more when the tick size is large, when the order is not expected to stand long and when prices are not volatile. Aitken et al. (1996) report that in 1993 about 6\% of orders on the Australian Stock Exchange (ASX) was undisclosed, accounting for approximately $28 \%$ of volume. Aitken et al. (2001) demonstrate that hidden quantities are used to reduce the option value of limit orders. More recently, Hasbrouck \& Saar (2002) document substantial use of undisclosed orders on the Island ECN. According to them, executed hidden orders constitute only about $3 \%$ of submitted limit orders but account for almost $12 \%$ of all order executions. Tuttle (2002) reports that hidden liquidity accounts for $22 \%$ of the inside depth in Nasdaq 100 stocks. Finally, D'Hondt et al. (2003) find that over December 2000 about $6 \%$ of orders submitted for 38 stocks belonging to the CAC40 index exhibits a hidden quantity. They highlight that undisclosed orders are mainly large-sized orders which are less likely to be totally filled but experience more cancellations and modifications than similar-sized usual orders. These results are confirmed by Raposo (2003).

In this paper, we assess hidden order placement on Euronext ${ }^{1}$ which is a transparent order-driven market. We especially focus on hidden order use for the 40 stocks included

\footnotetext{
${ }^{1}$ Euronext was created in September 2000 by the merger of the exchanges in Amsterdam, Brussels and Paris. It will be the first fully integrated, cross-border, European market for equities, bonds, derivatives and commodities. At present, Euronext includes respectively the former exchanges of Amsterdam, Brussels, Lisbonne, Paris and also the LIFFE.
} 
in the CAC40 index for the period covering October through December 2002. Based on full order book data, our empirical study has two main strands. On the one hand, we investigate the impact of hidden order use on both market depth and pretrade transparency. We define three different levels of depth on each market side: depth at the best limit, depth at the five best limits and depth in the whole order book. Then, thanks to the order book rebuilding, we compute the volume in value available at each order book level respectively for both market sides and we make a distinction between displayed quantities and hidden ones. Hence, we examine the magnitude of hidden depth, the behavior of both disclosed and undisclosed quantities and also interactions between short-term volatility and market depth composition. On the other hand, to detect and understand strategies involving hidden quantities, we analyze order aggressiveness and market conditions around order placement. First, we use the order classification proposed by Biais et al. (1995). Then, we look at interactions between the order flow and the order book. Therefore, we assess the influence of the spread size and both visible and hidden depths on order submission strategies. On both cases, we compare hidden order placement with usual order submission to highlight potential features in hidden order traders' behavior.

Though this study is in line with previous research, it also contributes in several points to the existing literature. Indeed, the full order book data we dispose allow us to extend previous empirical works about market liquidity and hidden orders. First, many papers dealing with market depth often focus on quantities available at the best quotes or on visible depth. In this paper, we assess market depth at several order book levels. Besides, we decompose it into its hidden and displayed components. It allows us to document substantially hidden depth magnitude and behavior, which was seldom reported in the past. Next, this study is the first to be devoted to hidden order submission strategies. Previous papers often investigate the use of hidden orders with respect to some stock features (tick size, volatility, trading volume). By examining the interactions between the order flow and the order book, this paper completes empirical findings about order placement in a transparent order-driven market. Based on a comparison between hidden and usual order submission, we report some characteristics of hidden order traders.

The main findings of our empirical work are the following ones. First of all, hidden orders have a large impact on market depth and pretrade transparency, especially at the top of the order book. We show that on average more than a third of the volume available at the 5 best limits is not visible on the market screens. Next, our results suggest that hidden order traders are mainly liquidity suppliers who submit orders within the 5 best limits of the order book. They also appear to focus on a given market side at a point in time and are less concerned with what happens on the opposite side. Finally, some hidden orders appear to be involved in splitting strategies. 
The remainder of the paper is organized as follows. Section 2 presents the theoretical context and an overview of the relevant literature. Section 3 describes our dataset and reports a lot of statistics about hidden order use in our sample. In the next section, we analyze the impact of undisclosed quantities on market depth composition and pretrade transparency. Section 5 is devoted to order placement strategies. Section 6 concludes.

\section{Theoretical Framework and Literature}

\subsection{Hidden Orders: A Trade-off between Liquidity and Trans- parency}

Order-driven trading systems collect and register all orders submitted by traders in an electronic limit order book with respect to their direction (buy or sell), their price (price priority) and their arrival time (time precedence). They match buy orders with sell orders satisfying their respective conditions (price/size). In this kind of market structure, traders are told liquidity suppliers or demanders according to the orders they use. Some orders offer liquidity by presenting other traders with trading opportunities. Other orders take liquidity by seizing those opportunities. Liquidity demanders submit market orders that give them guarantees of an immediate execution in return for a less profitable trade price. Liquidity suppliers expose standing limit orders that translate their trading interests and allow them to control the trade price. ${ }^{2}$ Actually, trades are easier to arrange when market participants actively publicize their trading intentions [Harris (1997)]. Therefore liquidity suppliers display limit orders to attract liquidity demanders. However, limit order traders expose themselves to various risks.

Liquidity suppliers benefit from limit order submission providing that they get better trade prices than liquidity demanders. Their profit proceeds from the difference between the market price and the limit price they specify in the order [Harris \& Hasbrouck (1996), Handa et al. (1997)]. However, limit order traders expose themselves to three risks. One of them is straight related to the level of pretrade market transparency. First, limit order traders take the risk of trading with better informed traders. Glosten (1994) refers to the adverse selection cost. Next, their limit orders may still remain unfilled [Foucault (1999)]. This inexecution risk can be associated with an opportunity cost. Finally, the information diffusion in real time influences the process of information inference and the revision of beliefs. In a transparent market, liquidity suppliers run the risk that parasitic traders infer information from their standing limit orders and use those at their expenses. Indeed, order exposure can be harmful if it reveals the traders' motives or the price impact of future trades or valuable free trading options. Front-runners try to infer securities values from the displayed order flow to get profit.

\footnotetext{
${ }^{2}$ Note that marketable limit orders take liquidity.
} 
Quote-matchers tend to benefit from implicit trading options. ${ }^{3}$ The behavior of those parasitic traders may increase the execution cost of limit orders.

Today order-driven markets have implemented facilities that help liquidity suppliers to control their order exposure risk. All of them allow limit order traders to cancel and/or modify their orders at any moment. Many markets like Euronext, the Toronto Stock Exchange or the Australian Stock Exchange also propose traders to use hidden orders. ECNs like Island offer limit order traders a no display option.

On Euronext, hidden orders, also called iceberg orders or undisclosed orders, allow traders to show other market participants only a part of the total quantity they want to buy or sell. The total order size is registered in the order book but only the order disclosed quantity is displayed on the market sheet. The order disclosed size must be at least 10 times the minimum trading lot. Hidden orders are placed in the order book according to their price and time precedences but only the disclosed size is visible on the market screens. When a hidden order is filled for its exposed size, the disclosed quantity is automatically renewed and the order joins the end of the order queue at the same limit price. Hidden orders lose thus their time priority after execution of the displayed quantity. Concerning size modifications, only the increase of the visible quantity results in a loss of time precedence. Hidden orders are accepted both in the pre-opening/closing phase and during the continuous trading session. At a call auction, hidden quantities contribute to the equilibrium price calculation. Once the auction price is given, buy (sell) hidden orders at a limit above (below) this price are fully filled. Hidden orders with a limit price equal to the equilibrium price receive priority for execution up to the displayed size. After execution of the exposed quantities, the disclosed quantity is automatically renewed and the order is positioned behind other orders at the same limit price and will be filled only after execution of fully disclosed orders.

From a theoretical point of view, hidden orders appear to be a real trade-off between market liquidity and market transparency. The ability to use hidden quantities involves an automatic splitting of orders and highlights interactions between the behavior of traders, market liquidity and the level of transparency. This kind of orders is for market participants a way of trading gradually according to the levels of both liquidity and transparency. They also allow transparent order-driven markets to compete with more opaque trading systems.

\subsection{Market Depth}

Roughly speaking, market liquidity reflects trading conditions. For Black (1971), the market for a stock is liquid if the following conditions hold: (i) there always exist bid and ask prices for a trader who wants to buy or sell small amounts of stock immediately; (ii)

\footnotetext{
${ }^{3}$ See Harris (1997) for more details.
} 
the bid-ask spread is always tight; (iii) a trader who is buying or selling a large amount of stock, in the absence of special information, can expect to do so over a long period of time at a price near, on average, the current market price; (iv) a trader can buy or sell a large block of stock immediately, but at a premium (or discount) positively related to the size of the block. From this complete definition, four properties are associated with the liquidity concept: immediacy, tightness, depth and resiliency. Immediacy is the time component of liquidity. Tightness refers to the cost of turning around a position over a short time. Kyle (1985) defines depth as the size of an order flow innovation required to change prices a given amount. Resiliency measures the speed with which prices recover from a liquidity shock.

Market depth refers to the quantities available at the quoted prices. Traders undergo an unfavorable price change when the size of their orders is larger than the quantity proposed at the best bid or ask price. Hence the market should be "deep" in that trading costs for large orders should also be small. In market microstructure literature, a lot of studies have been devoted to market depth assessment. The oldest ones define this liquidity measure as the total quantity available for trade at the best bid and ask quotes, ignoring orders outside the best prices [Lee et al. (1993), Ahn \& Cheung (1999), Ahn et al. (2001)...]. Nowadays, the access to more complete order data usually allows a more accurate estimation of market depth. For example, Danielsson \& Payne (2001) look at determination of order book depth on an electronic FX broking system. They define depth as the quantities available in the order book at or within 'k' ticks of the best limit price. They find that buy and sell side depths are uncorrelated while depth is strongly autocorrelated on the same market side.

Although market depth assessment becomes more and more sophisticated, few studies consider the potential presence of hidden quantities. One of the few papers devoted to hidden liquidity on the Paris Bourse ${ }^{4}$ is by Auguy \& Le Saout (1999). They focus on market depth by taking into account undisclosed quantities in the order book. By rebuilding the book for five stocks over 15 trading days, they show that the liquidity supply is much more plentiful than what market participants can see on the market sheet. The authors highlight on average $35 \%$ of hidden quantities in the order book. Moreover, they demonstrate that undisclosed depth can enhance other liquidity proxies like the Kyle's lambda or the weighted average spread. In a similar but more recent study, Tuttle (2002) describes the use of hidden depth in the Nasdaq market. She shows that hidden quantities represent $22 \%$ of the inside depth in Nasdaq 100 stocks. She proposes the idea that liquidity suppliers use hidden orders to mitigate adverse selection costs. According to the author, hidden depth has no significant effect on effective half-spreads incurred by traders but is predictive of future market price movements.

The current study builds partially upon and extends these empirical contributions

\footnotetext{
${ }^{4}$ The Paris Bourse is now called Euronext Paris.
} 
on market depth assessment. To analyze the impact of hidden orders on market liquidity, we first rebuild the order book for all the stocks included in the CAC40 index over the last three months of 2002. As in Danielsson \& Payne (2001), we distinguish different levels of depth on both market sides: depth at the best limit, depth at the five best limits and depth in the whole order book. Then, we compute the volume (in value) available at each order book level. However, similarly to Auguy \& Le Saout (1999) and Tuttle (2002), we decompose market depth into its visible and hidden components. Hence, we empirically investigate the magnitude of hidden depth, the behavior of both disclosed and undisclosed quantities and also interactions between short-term volatility and market depth composition.

\subsection{Order Submission Strategies}

To improve the understanding of traders' behavior, many empirical papers focus on order placement strategies. One of the most major studies is reported by Biais et al. (1995) who analyze the order flow dynamics on the Paris Bourse. They use very complete data that allow them to have access to the prices and the disclosed quantities available at each of the five best limits of the order book. ${ }^{5}$ To assess both supply and demand of liquidity, they define six categories of orders on each market side according to their aggressiveness. The three most aggressive order types result in an immediate execution. Large orders are orders to buy or sell at a better price a larger quantity than that available at the best opposite limit. Market orders are orders to buy or sell a quantity larger than that proposed at the best opposite limit, which are not allowed to walk up to the order book beyond the best limit. Small orders are orders to buy or sell a lower quantity than that available at the best opposite limit, which result in a full and immediate execution. Orders within the best quotes are orders which generate price improvement. Orders at the best quote join the queue of orders at the best bid or ask limit. Finally, orders below the best quote are orders to buy or sell below the best bid or ask price. ${ }^{6}$ With this order classification, Biais et al. (1995) highlight a competitive behavior of the liquidity suppliers. To gain price and time priority, traders quickly place orders within the best quotes when depth at the best limit or the spread is large. Their results are consistent with the presence of limit order traders monitoring the order book, competing to provide liquidity to the market when it is needed and rewarded, and quickly seizing favorable trading opportunities.

Following the example of a lot of authors [Bisière \& Kamionka (2000), Griffiths et al. (2000), Ranaldo (2001), Degryse et al. (2002), Beber \& Caglio (2003)...], we have chosen the order classification introduced by Biais et al. (1995) to investigate hidden order submission. In the current study, we first provide a comparative analysis

\footnotetext{
${ }^{5}$ The authors cannot observe directly hidden orders in their dataset.

${ }^{6}$ Orders to buy (sell) at a lower (higher) price than the best bid (ask).
} 
of aggressiveness levels for hidden and usual orders. Next, we examine interactions between the order book and the order flow. Thanks to our very complete order book data, we can assess the influence of respectively the spread size, both displayed and hidden depths and the last event on subsequent order aggressiveness.

\section{Euronext Data}

Euronext offers a particularly appropriate testing ground for examining hidden orders. First, Euronext is a very transparent order-driven market. So traders can see and use detailed information about the order book in their order placement strategies. Second, Euronext relies on a totally computerized and centralized trading system which facilitates the fully capture of order flow and execution process. The availability of very complete data makes feasible an empirical investigation of interactions between order submission strategies, order book dynamics and market liquidity.

Our intraday data refer to stocks included in the CAC40 index over the period covering October through December 2002. Table 1 makes list of these stocks ranked by decreasing market value. During this period, the trading day takes place in several stages. The market opens with a call auction following a pre-opening phase. Then, the market switches over to continuous trading and closes with a call auction following a short pre-closing period. All along the trading session, the trading system automatically feeds information into the electronic data dissemination network. Market participants thus receive in real time the five latest trades along with the five best limits of the order book with the associated disclosed quantities. ${ }^{7}$

For the study, we mainly use two datasets from the Euronext database. The order data contain all information about orders: submission date and time, limit price, size, order type, order state... For hidden orders, a distinction between the total order size and the disclosed one is made. The trade data provide information about all the trades: execution date and time, trade size, price... Those public data that Euronext authorities publish include very rich information about the trading process. Besides, we received additional information such as the identification codes and a variable indicating whether brokers act for their own account or not. As dual trading is allowed on Euronext, market members are brokers-dealers. Therefore a distinction can be made between "client orders" and "dual trader orders". This additional piece of information allows us to rebuild the order book ${ }^{8}$ over 63 trading days 9 for the 40 stocks of our sample.

Table 2 exhibits descriptive statistics about the cross-sectional distribution of daily

\footnotetext{
${ }^{7}$ The market members can observe at any time the entire content of the order book, except both the hidden quantities and the identification codes.

${ }^{8}$ For more details about order book rebuilding see De Winne \& D'Hondt (2003).

${ }^{9}$ We exclude December 24 from our sample period because the market closed at 2.00 p.m. this day.
} 
market activity for the CAC40 stocks over the three last months of 2002 . The results reflect the high level of trading activity in these stocks. The average daily number of trades per stock is 3 194, involving an average daily trading volume of 76017842 euros per stock. The average daily number of orders submitted per stock is 5244 . 221 among these orders contain a hidden quantity. If we compare these daily statistics with those of Biais et al. (1995), ${ }^{10}$ we may conclude that trading activity for the CAC40 stocks has dramatically intensified.

Summary statistics about orders submitted for the 40 stocks of our sample are presented in Table 3. First of all, we look at the magnitude of hidden order use. Globally, $4 \%$ of orders exhibit a hidden part. Previous studies provide results about hidden order submission on other markets. Aitken et al. (1996) report that, in 1993, about $6 \%$ of orders on the ASX was undisclosed. D'Hondt et al. (2002) find that, in 1997, about 14\% of limit orders on the French segment of Euro.NM was not fully displayed. Recently, Hasbrouck \& Saar (2002) document that executed hidden orders on Island represent only about $3 \%$ of submitted limit orders. However, a comparison with those findings would be difficult because both markets and stocks are not necessarily identical and hidden order submission is reported to be quite stock-dependent. Aitken et al. (2001) demonstrate that hidden order use is negatively related to relative tick size and trading activity but positively related to volatility and order value. Second, whether we focus on the trading stages, we find that the proportion of undisclosed orders is slightly larger over the continuous session than during the pre-opening/closing periods. This result is consistent with the hypothesis that the order exposure risk is higher in a continuous trading session because information dissemination in real time is more valuable during this period than over a pre-auction phase. For the rest, Table 3 shows that $48 \%$ of orders are submitted by brokers for their own account. However, dual traders seem to use a little more hidden quantities than their clients. Next, we can also note that traders use mainly limit orders. Finally, after computing order size quartiles per stock, we can see that undisclosed orders are essentially large orders. This result is consistent with Harris (1996) and D'Hondt et al. (2003) who report that hidden orders are larger than usual ones.

\section{Hidden Orders and Market Depth}

To assess the impact of hidden order use on market depth, we first rebuild the order book over the 63 trading days for each stock of our sample. Then, we define three different levels of depth on each market side: depth at the best limit, depth at the 5 best limits and depth in the whole order book. Hence, for each stock, we compute,

\footnotetext{
${ }^{10}$ Biais et al. (1995) report that in 1991 the average daily number of trades (orders) per CAC40 stock in their sample was 148.6 (160.6).
} 
at any time of the period, the volume in value ${ }^{11}$ available at each order book level on both market sides. However, to decompose market depth into its displayed and hidden components, we make a distinction between disclosed quantities and hidden ones. In this way, we are able to examine the behavior of both displayed and hidden depths over the continuous trading session. ${ }^{12}$

\subsection{Market depth decomposition}

First, we look at the proportion of visible depth at each level of the order book. For each stock, we compute the daily average ratio between the displayed quantities and the total (disclosed + hidden) quantities at each order book level respectively for each market side. Table 4 reports the daily average proportions of displayed depth for each CAC40 stock. We can see that, on average, more than $70 \%$ of the volume available in the whole order book is visible on both market sides. This proportion goes up to $80 \%$ for the quantities available at the best limit but decreases to $65 \%$ at the 5 best limits. In other words, one fifth of the volume available at the best prices is not displayed on the market screens. Furthermore, more than one third of depth is hidden at the 5 best limits. Consequently, from the magnitude of hidden depth, we can say that the impact of hidden order submission on market depth and pretrade transparency is quite large, especially at the 5 best limits of the order book. Table 4 also shows that the proportion of visible depth at the best limit doesn't vary very much across stocks or between market sides. She evolves from 0.69 to 0.88. However, this proportion changes a little more when we focus on the 5 best limits or on the whole order book. Some stocks, like LVMH MOET VUITTON (4213) or Crédit Lyonais (42349), exhibit the lowest daily average proportions of displayed depth, particularly on the bid side.

Second, we investigate the behavior of depth components over the trading day. To begin, we first partition each continuous trading session into 5-minute intervals. Then, we compute respectively for each stock, day and order book level, the time weighted average volumes in value available over each interval. Hence, we calculate the average total and visible volumes for each 5-minute interval across all stocks and all trading days. The results allow us to examine intraday patterns in depth composition at each order book level. Figure 1 shows depth average evolution in the whole order book. First, both total and displayed volumes available on both market sides increase slightly all along the trading session. The magnitude of hidden depth is thus quite constant over the session. This result is consistent with Auguy \& Le Saout (1999) and suggests that ingoing order flow is larger than outgoing one. Second, we see that both total and disclosed depths available on the sell side are larger than on the buy

\footnotetext{
${ }^{11}$ To allow comparisons between stocks, we multiply the number of shares available by the opening price of the day.

${ }^{12}$ We focus exclusively on the continuous session (between 9.00 a.m and 5.30 p.m) because depth behavior is mainly increasing during pre-auction phases.
} 
side. This finding may be due to the bearish tendency of our sample period. Figure 2 exhibits depth average behavior at the 5 best limits of the order book. Depth pattern at this level is quite different than in the whole order book. Indeed, total depth on both sides of the market varies a lot over the continuous session while displayed depth looks more stable. Figure 3 provides a more striking result for hidden depth behavior at the best limit of the order book. The disclosed volumes are quite constant while the total volumes move much more. All these results are similar for the 40 stocks of our sample and are consistent with Auguy \& Le Saout (1999) who demonstrate that changes in total depth are mainly explained by variations in hidden quantities, especially at the best limit of the order book. These findings suggest that there is a real management of disclosed depth at the top of the order book, which is publicly diffused in real time. Consequently, we may suppose that displayed depth should play a significant role in the decision of hiding orders or not.

\subsection{Market depth composition and short-term volatility}

Ahn et al. (2001) report that short-term volatility affects order flow composition and thus market depth. To examine explicitly how order flow composition is related to the liquidity-driven price volatility, they decompose the short-term volatility into upside and downside measures. According to them, when there is a paucity of limit orders on the ask (bid) side, the temporary order imbalance results in upside (downside) volatility. This will encourage traders to place more limit sell (buy) orders. Hence the authors demonstrate that short-term volatility arising from the ask (bid) side at time $t-1$ induces traders to submit limit sell (buy) orders rather than market sell (buy) orders at time $t$, so that market depth on the ask (bid) side increases.

Similarly, we investigate in this paper the influence of short-term volatility on market depth composition. Theoretically, price volatility encourages limit order submission [Handa et al. (1997), Foucault (1999)]. However, price volatility also affects the order exposure risk. Copeland \& Galai (1983) explain that the option value of limit orders is affected by volatility. Furthermore, Harris (1996) find that traders expose more limit orders when prices are not volatile. Therefore, price volatility should induce traders to use more hidden orders. Hence price volatility arising from the ask (bid) side should have an impact on sell (buy) market depth composition, so that hidden depth proportion on the ask (bid) side is expected to be positively related to upside (downside) price volatility.

To address the above hypothesis, we conduct an empirical analysis on a 5-minute intervals basis and we estimate the following regressions:

$$
H D P_{t}^{5 b i d s}=\alpha_{1}+\beta_{1}^{+} R I S K_{t-1}^{+}+\beta_{1}^{-} R I S K_{t-1}^{-}+\rho_{1} H D P_{t-1}^{5 b i d s}+\epsilon_{t}^{5 b i d s}
$$




$$
H D P_{t}^{5 a s k s}=\alpha_{2}+\beta_{2}^{+} R I S K_{t-1}^{+}+\beta_{2}^{-} R I S K_{t-1}^{-}+\rho_{2} H D P_{t-1}^{5 a s k s}+\epsilon_{t}^{5 a s k s}
$$

where $H D P_{t}^{5 b i d s}$ is the time weighted average hidden depth proportion at the 5 best bids during time interval $t, H D P_{t}^{5 a s k s}$ is the time weighted average hidden depth proportion at the 5 best asks during time interval $t, R I S K_{t-1}^{+}$and $R I S K_{t-1}^{-}$are the upside and downside volatility during time interval $t-1$. The upside (downside) volatility is computed as the sum of absolute returns based on positive (negative) return observations within the interval $t-1 .^{13} \epsilon_{t}^{5 b i d s}$ and $\epsilon_{t}^{5 a s k s}$ are usual random error terms. The inclusion of $H D P_{t-1}^{5 b i d s}$ and $H D P_{t-1}^{5 a s k s}$ allows to control for autocorrelation in hidden depth magnitude. We estimate equations 1 and 2 using Generalized Method of Moments. Estimates are calculated cross-sectionally and presented in Table 5.

First, $H D P_{t}^{5 b i d s}\left(H D P_{t}^{5 a s k s}\right)$ is positively and significantly related to the downside (upside) volatility. This confirms our expectations. When liquidity-driven price volatility arises from the bid (ask) side, this induces potential buyers (sellers) to submit hidden buy (sell) orders because the exposure risk is higher. Second, it is interesting to note that $H D P_{t}^{5 b i d s}\left(H D P_{t}^{5 a s k s}\right)$ is negatively related to upside (downside) volatility. Ahn et al. (2001) indicate that when the price moves up (down), traders submit market buy (sell) orders instead of limit buy (sell) orders because of the probability of execution. Besides, Table 3 shows us that hidden orders are only limit orders. This might explain why hidden depth proportion decreases on the bid (ask) side when the upside (downside) volatility increases. Finally, whatever the market side, the proportion of hidden depth is positively autocorrelated. The coefficients $\rho$ are positive and significant for both equations.

\section{$5 \quad$ Hidden Order Submission Strategies}

Over the period covering October through December 2002, 12059812 orders were submitted during the continuous trading session for the 40 stocks of our sample. The order book rebuilding allows us to associate each order with the state of the order book just before its introduction. To take into account the time a trader needs to react to what he can observe on the market screens [Kaniel \& Liu (2001)], we implement a delay of 5 seconds between the placement time of any order and the state of the order book referring to it.

\subsection{Order Aggressiveness Analysis}

To delimit the order submission activity in the order book, we first compute the proportion of orders placed within the 5 best limits. We consider as orders within the 5

\footnotetext{
${ }^{13}$ Like Ahn et al. (2001), we implicitly assume that the mean return is zero and we measure the cumulative price fluctuation within the interval rather than the average price fluctuation for each trade.
} 
best limits both orders resulting in an immediate execution when submitted and buy (sell) orders with a limit price equal or higher (lower) than the fifth best price prevailing on the bid (ask) side of the order book when submitted. In our sample, we find that on average $90 \%$ of all orders (with a hidden part or not) join the 5 best limits of the book when submitted. Most of the order placement activity is thus concentrated at the top of the order book, which is diffused in real time on the market screens.

Next, we use the methodology of Biais et al. (1995) described in subsection 2.3 to categorize orders. Identically, we define the level of order aggressiveness according to the time for execution. We infer it from order price and size in comparison with both the price and the displayed quantities available at the best limit on the opposite side of the order book. ${ }^{14}$ To identify potential disparities in aggressiveness, we conduct this classification respectively for usual and hidden orders. Table 6 reports the unconditional probabilities of orders according to their aggressiveness level on each market side. These results reveal that for usual and hidden orders the most frequent order type is orders placed below the best quote on each market side. However, if we consider the other categories, a quite striking difference appears: on average $36 \%$ of usual orders takes liquidity by resulting in an immediate execution when they arrive on the market while only $18 \%$ of hidden orders does likewise. Hence, few hidden orders are aggressive in comparison with usual ones. On the one hand, the first two categories constitute only $14 \%$ of them. This phenomenon may be explained by Euronext requirements for acceptance of undisclosed quantities. Indeed, hidden quantities are prohibited with must be filled orders which are very aggressive orders. On the other hand, only $4 \%$ of hidden orders are classified as "small orders", which represents a significant difference with usual orders. This finding can be related to one of our previous results that state that hidden orders are mainly large-sized orders. If we take into account only the disclosed quantity of hidden orders to define their aggressiveness level, we will observe a significant switch from category 2 to category 3. In this case, the frequency of "small orders" might increase although the most frequent events would remain hidden orders submitted below the best quote. To summarize, in comparison with usual orders, hidden orders are mainly liquidity providing. Less than $20 \%$ of hidden orders takes liquidity when submitted. Therefore, hidden order traders appear to be liquidity suppliers rather than liquidity demanders.

Finally, to check whether hidden order traders are really liquidity providers, we focus on orders included in category 6 . Indeed, orders placed far away from the best quote do not really enhance market liquidity. In our sample, 3630995 (180 279) usual (hidden) orders are registered below the best quote in the order book when submitted. For both order types, we first look at the proportion of them placed within the 5 best limits. $65 \%(68 \%)$ of usual (hidden) orders are submitted below the best quote but

\footnotetext{
${ }^{14}$ For an order aggressiveness analysis dealing with both disclosed and hidden quantities, see De Winne \& D'Hondt (2003).
} 
within the 5 best limits. Then, to analyze more precisely order submission within the 5 best limits, we compute for each buy (sell) order the difference between the order price and the best bid (ask). To get a benchmark, we also calculate the difference between the price at the best limit and the price at the fifth best limit. Table 7 exhibits statistics about these differences expressed in number of ticks. First, we can infer from this table that, whatever the tick size, more than $50 \%$ of orders (with a hidden part or not) below the best quote are placed within the 5 best limits. Indeed, the median difference for both usual and hidden orders is always smaller than the number of ticks between the best limit and the fifth best price. Moreover, for a tick of 0.05 or 0.1 , at least $75 \%$ of hidden orders join the 5 best limits when submitted but this finding does not hold for usual orders. Furthermore, usual orders are on average registered farther in the order book than hidden ones. For example, when the tick size is 0.01, usual orders are on average registered at 43 ticks away from the best quote while hidden orders are on average ranked at 23 ticks away from the best price. Hence, hidden order submission is more concentrated within the 5 best limits than usual order placement. Consequently, hidden order traders appear to be mainly real liquidity suppliers who monitor in real time the 5 best limits of the order book.

\subsection{Market Conditions around Order Placement}

In this subsection, we focus on how the state of the order book can affect hidden order placement. The high quality of the data we get with the order book rebuilding allows us a detailed investigation of market conditions around order submission. We analyze interactions between the order book and the order flow as in Biais et al. (1995). First, we examine the order flow given the state of the order book. Second, we look at the probabilities of orders conditional on the last event. In both cases, we compare hidden order submission with usual order placement. Our goal is to highlight potential features in hidden order traders' behavior.

The empirical frequencies of the different order types conditional on the previous order book state respectively for usual and hidden orders are reported in Tables 8 and 9. Identically to Biais et al. (1995), we aggregate for simplicity orders resulting in an immediate execution when submitted. The state of the order book is characterized by the spread size and the depth available at the best limit on both market sides. Note that we distinguish displayed and hidden quantities available at the best quotes. Hence observations are classified in several steps. First of all, orders are divided into two categories according to whether the prevailing spread is larger or smaller than the daily median for the given stock. Next, we classify orders of both subsamples according to respectively the displayed depth at the best bid, the displayed depth at the best ask, the hidden depth at the best bid and the hidden depth at the best ask. For each stock, each kind of depth is defined to be small if it's smaller than its daily median. 
Griffiths et al. (2000) find that aggressive orders are more likely when the order book immediately prior to the order has a narrow spread, large depth on the same market side as the order and small depth on the opposite side. Our results are consistent with theirs. First, the spread influence on order placement is similar for both usual and hidden orders. Purchases and sales are more frequent when the spread is narrow while buy and sell orders within the quotes are more likely when the spread is large. Biais et al. (1995) highlight these liquidity effects. Traders supply liquidity when it's scarce and take it when it's plentiful. Second, usual orders tend to be more aggressive when the displayed depth is large on the same market side or small on the opposite market side. This reflects undercutting behavior and competition among traders on the same market side. Moreover, usual orders are more likely to be aggressive when the hidden depth is large on the opposite market side. When the spread is narrow, $28 \%$ $(31 \%)$ of buy (sell) usual orders generate an immediate trade when the hidden depth on the ask (bid) side is large at the best limit. This phenomenon could be explained by traders who discover hidden quantities available at the best opposite limit and try to trade against them again. As for hidden orders, results are quite similar but less pronounced. Indeed, the magnitude of displayed depth available at the best bid (ask) seems to have less impact on sell (buy) hidden order aggressiveness. This could suggest that hidden order traders focus on a given market side at a point in time and are less concerned with what happens on the opposite market side than usual order traders. Furthermore, whatever the side of the order book, the hidden depth doesn't really affect hidden order aggressiveness. This finding may be related to the automatic splitting involved by hidden orders. Indeed, undisclosed quantities are probably more difficult to be discovered with hidden orders which are often filled progressively.

To analyze the impact of the last order on subsequent order aggressiveness, we present the transition probability matrix for usual (hidden) orders only in Table 10 (11). ${ }^{15}$ These contingency tables exhibit the empirical frequencies of each order category conditional upon the type of the previous event. To examine how the probability of a given order varies as a function of the previous one, we compare frequencies within each column. First, for both hidden and usual orders, we find the diagonal effect as reported in Biais et al. (1995) and more recently in Degryse et al. (2002). The probability that a given order type occurs is thus larger just after the same kind of order than unconditionally. In other words, an order of a given type is likely to be followed by an order of the same type. However, this diagonal effect appears especially pronounced for hidden orders placed below the best quote. Second, we can also observe in Tables 10 and 11 that buy (sell) orders within the quotes are also likely after sell (buy) orders within the spread. This interaction between both market sides leads to a

\footnotetext{
${ }^{15}$ To facilitate interpretation, we do not report the transition probability matrix for usual and hidden orders together. However, results from this table are quite similar but less striking because we have much more usual orders than hidden ones.
} 
spread decrease and is more pronounced for hidden orders. This result suggests that traders on the same market side but also traders on the opposite market side compete to supply liquidity.

In the microstructure literature, three explanations are generally proposed for the diagonal effect. It could result from strategic order splitting, from imitating behavior or from similar reactions successively to the same event. To test the order splitting hypothesis, we examine the identification code associated with each order. Indeed, our order data identify the broker submitting the orders as well as the account (client or own) for which the orders are placed. Hence, we assume that two similar consecutive orders submitted by the same broker for the same account are split orders. ${ }^{16}$ Then, we compute the average proportion of split orders for each pair of identical successive orders. This proportion is calculated stock by stock to allow statistical comparisons between usual and hidden orders. ${ }^{17}$ To facilitate interpretation, we present the global average proportions in Table 12. For usual orders, the global average proportion of split orders fluctuate from 30 to $46 \%$ without any difference between market sides. As for hidden orders, those proportions are often significantly larger. ${ }^{18}$ Actually, more than $90 \%$ of successive hidden orders of categories 1, 3, 7 and 9 can be defined as split orders. This also holds for around $70 \%$ of hidden orders consecutively placed below the best price. Consequently, similar successive hidden orders appear to be more involved in splitting strategies than similar successive usual orders. Therefore, hidden order submission should not be considered as a simple alternative to splitting strategies for large orders.

\section{Conclusion}

This paper is devoted to hidden order placement for all the stocks belonging to the CAC40 index over the period covering October through December 2002. The dataset we received from the market authorities allows us to rebuild the order book over 63 trading days for the 40 stocks of our sample. Based on these data, our empirical study has two main strands. First, we investigate the impact of hidden order use on market depth and pretrade transparency. We define three different levels of depth on each market side: depth at the best limit, depth at the five best limits and depth in the whole order book. Then, thanks to the order book rebuilding, we compute the volume in value available at each order book level for both market sides with a distinction between displayed quantities and hidden ones. Hence we examine the magnitude of hidden depth, the behavior of both disclosed and undisclosed quantities and interac-

\footnotetext{
${ }^{16} \mathrm{~A}$ similar assumption is also used by Ellul et al. (2003).

${ }^{17}$ Both t-test and Wilcoxon test were conducted.

${ }^{18}$ Only the average proportions of categories 4, 10 and 11 for hidden orders are not significantly different (at the $1 \%$ level) from the corresponding average proportions for usual orders.
} 
tions between short-term volatility and market depth composition. Second, to detect and understand strategies involving hidden quantities, we analyze order aggressiveness and market conditions around order placement. First, we use the order classification proposed by Biais et al. (1995). Then, we look at interactions between the order flow and the order book. We assess the influence of the spread size and both displayed and hidden depths on order submission strategies. Actually, we compare hidden order placement with usual order submission to highlight potential features in hidden order traders' behavior.

The main results of our empirical work are the following ones. First, the impact of hidden orders on market depth and pretrade transparency is quite large, especially at the top of the order book. Indeed, around 35\% (20\%) of depth is hidden at the 5 best limits (at the best limit). On average, more than one third of quantities available at the 5 best limits is thus not displayed on the market screens. Second, our analysis of depth behavior provides evidence for a real management of disclosed depth at the top of the order book. The hidden depth at the 5 best limits on both market sides varies a lot all along the continuous trading session while the displayed depth is much more stable. Hence, the latter should play a significant role in the decision of hiding orders or not. Third, we highlight that short-term volatility influences market depth composition. The liquidity-driven price volatility arising from the bid (ask) side encourages hidden buy (sell) order placement. Fourth, our order aggressiveness analysis reveals that hidden order traders are mainly real liquidity suppliers who focus especially on the 5 best limits of the order book. Next, the spread influence on order placement is similar for both usual and hidden orders. Purchases and sales are more likely when the prevailing spread is narrow whereas orders within the quotes are more frequent when the spread is large. As for depth impact, usual orders are more likely to be aggressive when the displayed depth is large (small) on the same (opposite) market side or the hidden depth is large on the opposite market side. However, the magnitude of both displayed and hidden depths available on the opposite market side doesn't really affect hidden order submission. Hidden order traders appear to focus on a given market side at a point in time and seem less concerned with what happens on the opposite market side. Finally, we find evidence that hidden orders are more involved in splitting strategies than usual orders. 


\section{References}

Ahn, H., Bae, K. \& Chan, K. (2001), 'Limit orders, depth and volatility: Evidence from the Stock Exchange of Hong Kong', Journal of Finance 56, 767-788.

Ahn, H. \& Cheung, Y. (1999), 'The intraday patterns of the spread and depth in a market without market makers: The Stock Exchange of Hong Kong', Pacific Basin Finance Journal 7, 539-556.

Aitken, M., Berkman, H. \& Mak, D. (2001), 'The use of undisclosed limit orders on the Australian Stock Exchange', Journal of Banking 63 Finance 25, 1589-1603.

Aitken, M., Brown, P. \& Walter, T. (1996), 'Infrequent trading and firm size effects as explanations for intraday patterns in returns on SEATS', Working Paper.

Auguy, M. \& Le Saout, E. (1999), 'La liquidité réelle à la Bourse de Paris: De nouvelles estimations (une étude du règlement mensuel)', Papier présenté à l'AFFI.

Beber, A. \& Caglio, C. (2003), 'Order submission strategies and information: Empirical evidence from the NYSE', Working Paper.

Biais, B., Hillion, P. \& Spatt, C. (1995), 'An empirical analysis of the limit order book and the order flow in the Paris Bourse', Journal of Finance 50(5), 1655-1689.

Bisière, C. \& Kamionka, T. (2000), 'Timing of orders, orders aggressiveness and the order book in the Paris Bourse', Annales d'Economie et de Statistiques (60).

Black, F. (1971), 'Towards a fully automated exchange,first part', Financial Analysts Journal 27, 29-34.

Copeland, T. \& Galai, D. (1983), 'Information effects on the bid-ask spread', Journal of Finance 38, 1457-1469.

Danielsson, J. \& Payne, R. (2001), 'Measuring and explaining liquidity on an electronic limit order book : Evidence from Reuters D2000-2', Working Paper .

De Winne, R. \& D'Hondt, C. (2003), 'Rebuilding the limit order book on Euronext or how to improve market liquidity assessment', Working Paper.

Degryse, H., de Jong, F., Van Ravenswaaij, M. \& Wuyts, G. (2002), 'Aggressive orders and the resiliency of a limit order market', Working Paper.

D'Hondt, C., De Winne, R. \& François-Heude, A. (2002), 'Hidden orders: An empirical study on a Call Auction Market', Working Paper.

D'Hondt, C., De Winne, R. \& François-Heude, A. (2003), 'Hidden Orders in auction and continuous trading: An empirical study on Euronext', Working Paper. 
Ellul, A., Holden, C., Jain, P. \& Jennings, R. (2003), 'Determinants of order choice on the New York Stock Exchange', Working Paper .

Foucault (1999), 'Order flow composition and trading costs in a dynamic limit order market', Journal of Financial Markets 2, 99-134.

Glosten, L. (1994), 'Is the electronic open limit order book inevitable?', Journal of Finance 49(4), 1127-1161.

Griffiths, Smith, Turnbull \& White (2000), 'The costs and determinants of order aggressiveness', Journal of Financial Economics 56, 65-88.

Handa, P., Schwartz, R. A. \& Tiwari, A. (1997), 'L'écologie d'un marché dirigé par les ordres', Organisation et Qualité Des Marchés Financiers pp. 187-202.

Harris, L. (1996), 'Does a large minimum price variation encourage order exposure?', Working Paper .

Harris, L. (1997), 'Order exposure and parasitic traders', Working Paper .

Harris, L. \& Hasbrouck, J. (1996), 'Market vs. limit orders: The superDOT evidence on order submission strategy', Journal of Financial and Quantitative Analysis 31(2), 213-231.

Hasbrouck, J. \& Saar, G. (2002), 'Limit orders and volatility in a hybrid market: The Island ECN', Working Paper .

Kaniel, R. \& Liu, H. (2001), 'So what orders do informed traders use?', Working Paper

Kyle, A. S. (1985), 'Continuous auctions and insider trading', Econometrica 53(6), 1315-1335.

Lee, C., Mucklow, B. \& Ready, M. (1993), 'Spreads,depths,and the impact of earnings information: An intraday analysis', The Review of Financial Studies 6(2), 345374 .

Ranaldo, A. (2001), 'Order aggressiveness', Working Paper .

Raposo, J. (2003), 'Les stratégies de placement d'ordres: la cas des ordres à quantité cachée', Working Paper.

Tuttle, L. (2002), 'Hidden orders, trading costs and information', Working Paper. 
Tables and figures

List of stocks belonging to the CAC40 index

\begin{tabular}{|c|c|c|}
\hline Code & Name & Market value \\
\hline 4161 & TOTAL FINA ELF & 94968905182 \\
\hline 4166 & OREAL & 49622962544 \\
\hline 25743 & $A V E N T I S$ & 42491517822 \\
\hline 4157 & SANOFI SYNTHELABO & 41807670827 \\
\hline 26990 & $B N P P A R I B A S$ & 29719771455 \\
\hline 4154 & $C A R R E F O U R$ & 29157761966 \\
\hline 55149 & ORANGE & 22628445583 \\
\hline 4462 & SOCIETE GENERALE & 18678726421 \\
\hline 4213 & LVMH MOET VUITTON & 18078690429 \\
\hline 4188 & GROUPE DANONE & 17350188574 \\
\hline 4180 & $S U E Z$ & 16764208315 \\
\hline 4187 & $A X A$ & 16747788709 \\
\hline 72275 & CREDIT AGRICOLE & 15156752325 \\
\hline 4150 & AIRLIQUIDE & 12652195278 \\
\hline 4245 & $V I V E N D I U N I V E R S A L$ & 12519113337 \\
\hline 29512 & $R E N A U L T$ & 12295036642 \\
\hline 29636 & ST MICROELECTRONICS & 12154957808 \\
\hline 42349 & CREDIT LYONNAIS & 11528687052 \\
\hline 4181 & $L A F A R G E$ & 10845082838 \\
\hline 4292 & SCHNEIDER ELECTRIC & 10621969271 \\
\hline 45057 & $D E X I A$ & 10528766064 \\
\hline 4252 & PEUGEOT & 9773596987 \\
\hline 4178 & $B O U Y G U E S$ & 8937838936 \\
\hline 49388 & $E A D S$ & 8747187814 \\
\hline 36064 & $F R A N C E T E L E C O M$ & 8583835968 \\
\hline 49471 & VIVENDI ENVIRON. & 8243339548 \\
\hline 4250 & PINAULT PRINTEMPS & 7772049480 \\
\hline 4322 & $S A I N T$ GOBAIN & 7748000691 \\
\hline 4353 & $C A S I N O G U I C H A R D$ & 6190074050 \\
\hline 4170 & $A C C O R$ & 5976229500 \\
\hline 4448 & $L A G A R D E R E$ & 5419796693 \\
\hline 4351 & $V I N C I$ & 5212842310 \\
\hline 223 & $A G F$ & 4829133422 \\
\hline 1526 & $T F 1$ & 4584769199 \\
\hline 4237 & THALES & 4535460112 \\
\hline 44450 & THOMSON MULTIMEDIA & 4428081156 \\
\hline 4234 & MICHELIN & 3851747013 \\
\hline 4230 & SODEXHO ALLIANCE & 3106085317 \\
\hline 4438 & $A L C A T E L$ & 2924479010 \\
\hline 4340 & $C A P G E M I N I$ & 2026487546 \\
\hline
\end{tabular}

Table 1: This table presents, for each stock belonging to the CAC40 index, the market code, the name and also the market value estimated on October 1, 2002. 
Cross-sectional distribution of daily market activity

\begin{tabular}{|c|c|c|c|c|}
\hline \hline Statistic & Mean & Max & Median & Min \\
\hline \hline Daily return & -0.0010 & 0.2499 & -0.0020 & -0.1743 \\
Hi - Lo & 0.0532 & 0.3351 & 0.0468 & 0.0084 \\
Number of trades & 3194 & 27438 & 2373 & 329 \\
Trading volume (shares) & 2957175 & 87625404 & 1357942 & 76603 \\
Trading volume (euros) & 76017842 & 1017806085 & 44971865 & 3475230 \\
Number of orders & 5244 & 33579 & 4185 & 840 \\
Number of hidden orders & 221 & 1025 & 194 & 10 \\
Number of dual trader orders & 2508 & 25501 & 2016 & 321 \\
\hline \hline
\end{tabular}

Table 2: For the 63 trading days and for each stock of our sample, we compute the daily return, difference between highest and lowest price divided by the lowest price, number of trades, trading volume in shares and in euros, number of orders, number of hidden orders and number of dual trader orders. This table presents summary statistics about the cross-sectional distribution of these daily averages across all the stocks included in the CAC40 index.

Summary statistics about orders

\begin{tabular}{|c|c|c|c|c|}
\hline & Usual Orders & Hidden Orders & All Orders & \\
\hline All the sample & $\begin{array}{c}12658489 \\
96 \%\end{array}$ & $\begin{array}{c}556098 \\
4 \%\end{array}$ & $\begin{array}{c}13214587 \\
100 \%\end{array}$ & $100 \%$ \\
\hline Continuous session & $\begin{array}{c}11543902 \\
96 \%\end{array}$ & $\begin{array}{c}515910 \\
4 \%\end{array}$ & $\begin{array}{c}12059812 \\
100 \%\end{array}$ & $\mathbf{9 1 \%}$ \\
\hline Pre-opening/closing periods & $\begin{array}{c}1114587 \\
97 \%\end{array}$ & $\begin{array}{c}40188 \\
3 \%\end{array}$ & $\begin{array}{c}1154775 \\
100 \%\end{array}$ & $\mathbf{9} \%$ \\
\hline Client orders & $\begin{array}{c}6589280 \\
96 \%\end{array}$ & $\begin{array}{c}263733 \\
4 \%\end{array}$ & $\begin{array}{c}6853013 \\
100 \%\end{array}$ & $\mathbf{5 2} \%$ \\
\hline Dual trader orders & $\begin{array}{c}6069209 \\
95 \%\end{array}$ & $\begin{array}{c}292365 \\
5 \%\end{array}$ & $\begin{array}{c}6361574 \\
100 \%\end{array}$ & $48 \%$ \\
\hline Limit orders & $\begin{array}{c}11459505 \\
95 \%\end{array}$ & $\begin{array}{c}556098 \\
5 \%\end{array}$ & $\begin{array}{c}12015603 \\
100 \%\end{array}$ & $\mathbf{9 1} \%$ \\
\hline Market orders & $\begin{array}{c}1198984 \\
100 \%\end{array}$ & $\begin{array}{c}0 \\
0 \%\end{array}$ & $\begin{array}{c}1198984 \\
100 \%\end{array}$ & $\mathbf{9} \%$ \\
\hline Small orders & $\begin{array}{c}3531605 \\
28 \%\end{array}$ & $\begin{array}{c}19823 \\
4 \%\end{array}$ & 3551428 & $\mathbf{2 5} \%$ \\
\hline Inferior median orders & $\begin{array}{c}3253102 \\
26 \%\end{array}$ & $\begin{array}{c}28353 \\
5 \%\end{array}$ & 3281455 & $\mathbf{2 5} \%$ \\
\hline Superior median orders & $\begin{array}{c}3167399 \\
25 \%\end{array}$ & $\begin{array}{c}57983 \\
10 \%\end{array}$ & 3225382 & $\mathbf{2 5} \%$ \\
\hline Large orders & $\begin{array}{c}2706383 \\
21 \%\end{array}$ & $\begin{array}{c}449939 \\
81 \%\end{array}$ & 3156322 & $\mathbf{2 5} \%$ \\
\hline
\end{tabular}

Table 3: For both usual and hidden orders, we look at the submission time, the initiator (broker or client), the order type and the order size. For each stock, we compute order size quartiles per day and we define 4 order size categories: small orders $(<\mathrm{Q} 1)$, inferior median orders (Q1-Me), superior median orders (Me-Q3) and large orders (>Q3). 


\section{Daily average proportions of displayed depth}

\begin{tabular}{|c|c|c|c|c|c|c|}
\hline \hline Stock & RB1 & RA1 & RB5 & RA5 & $R B$ & $R A$ \\
\hline \hline 223 & 0.86 & 0.87 & 0.73 & 0.74 & 0.83 & 0.84 \\
1526 & 0.78 & 0.78 & 0.59 & 0.58 & 0.68 & 0.64 \\
4150 & 0.84 & 0.84 & 0.71 & 0.71 & 0.61 & 0.83 \\
4154 & 0.80 & 0.81 & 0.68 & 0.69 & 0.54 & 0.77 \\
4157 & 0.82 & 0.83 & 0.71 & 0.72 & 0.78 & 0.65 \\
4161 & 0.88 & 0.87 & 0.81 & 0.79 & 0.83 & 0.90 \\
4166 & 0.81 & 0.82 & 0.70 & 0.72 & 0.87 & 0.77 \\
4170 & 0.80 & 0.81 & 0.62 & 0.64 & 0.64 & 0.72 \\
4178 & 0.78 & 0.79 & 0.62 & 0.63 & 0.78 & 0.81 \\
4180 & 0.82 & 0.81 & 0.71 & 0.68 & 0.86 & 0.84 \\
4181 & 0.83 & 0.80 & 0.70 & 0.65 & 0.78 & 0.83 \\
4187 & 0.78 & 0.80 & 0.67 & 0.68 & 0.78 & 0.79 \\
4188 & 0.81 & 0.81 & 0.63 & 0.64 & 0.69 & 0.72 \\
4213 & 0.80 & 0.80 & 0.63 & 0.63 & 0.51 & 0.60 \\
4230 & 0.81 & 0.81 & 0.63 & 0.60 & 0.64 & 0.60 \\
4234 & 0.81 & 0.83 & 0.66 & 0.68 & 0.80 & 0.60 \\
4237 & 0.79 & 0.80 & 0.63 & 0.62 & 0.77 & 0.75 \\
4245 & 0.78 & 0.78 & 0.66 & 0.66 & 0.81 & 0.86 \\
4250 & 0.80 & 0.78 & 0.65 & 0.62 & 0.71 & 0.71 \\
4252 & 0.80 & 0.80 & 0.65 & 0.63 & 0.70 & 0.68 \\
4292 & 0.79 & 0.80 & 0.63 & 0.62 & 0.72 & 0.74 \\
4322 & 0.79 & 0.77 & 0.65 & 0.62 & 0.73 & 0.69 \\
4340 & 0.76 & 0.77 & 0.57 & 0.59 & 0.65 & 0.72 \\
4351 & 0.77 & 0.77 & 0.61 & 0.62 & 0.70 & 0.75 \\
4353 & 0.80 & 0.83 & 0.66 & 0.71 & 0.77 & 0.57 \\
4438 & 0.84 & 0.83 & 0.80 & 0.79 & 0.92 & 0.93 \\
4448 & 0.84 & 0.82 & 0.71 & 0.66 & 0.74 & 0.70 \\
4462 & 0.80 & 0.80 & 0.69 & 0.68 & 0.75 & 0.82 \\
25743 & 0.81 & 0.83 & 0.72 & 0.72 & 0.71 & 0.69 \\
26990 & 0.78 & 0.78 & 0.67 & 0.66 & 0.71 & 0.78 \\
29512 & 0.78 & 0.78 & 0.62 & 0.62 & 0.69 & 0.72 \\
29636 & 0.89 & 0.91 & 0.87 & 0.89 & 0.79 & 0.84 \\
36064 & 0.80 & 0.82 & 0.69 & 0.71 & 0.89 & 0.90 \\
42349 & 0.69 & 0.78 & 0.53 & 0.63 & 0.56 & 0.72 \\
44540 & 0.78 & 0.80 & 0.61 & 0.63 & 0.67 & 0.70 \\
45057 & 0.79 & 0.80 & 0.70 & 0.70 & 0.69 & 0.55 \\
49388 & 0.77 & 0.77 & 0.60 & 0.59 & 0.75 & 0.52 \\
49471 & 0.80 & 0.77 & 0.65 & 0.59 & 0.83 & 0.81 \\
55149 & 0.78 & 0.77 & 0.68 & 0.68 & 0.85 & 0.89 \\
72275 & 0.79 & 0.76 & 0.66 & 0.64 & 0.85 & 0.92 \\
\hline Mean & 0.80 & 0.80 & 0.66 & 0.66 & 0.74 & 0.74 \\
Median & 0.80 & 0.80 & 0.65 & 0.65 & 0.74 & 0.74 \\
\hline \hline & & & & & & \\
\hline
\end{tabular}

Table 4: This table reports, for each stock, the daily average ratio between the displayed quantities and the total (disclosed + hidden) quantities at each level of the order book for both market sides. RB1 (RA1) refers to the daily average ratio for the best bid (ask), RB5 (RA5) refers to the daily average ratio for the 5 best limits on the bid (ask) side and RB (RA) refers to the daily average ratio for the complete order book on the bid (ask) side. Both mean and median ratios for each order book level are also provided. 


\section{GMM estimates for regression of hidden depth proportion on lagged upside and downside volatility}

\begin{tabular}{|c|c|c|c|c|c|}
\hline \hline \multicolumn{3}{|c|}{$B I D S I D E$} & \multicolumn{3}{c|}{$A S K S I D E$} \\
\hline$\beta_{1}^{+}$ & $\beta_{1}^{-}$ & $\rho_{1}$ & $\beta_{2}^{+}$ & $\beta_{2}^{-}$ & $\rho_{2}$ \\
\hline \hline$-0.6135^{* * *}$ & $0.4972^{* * *}$ & $0.7795^{* * *}$ & $0.1619^{* * *}$ & $-0.2587^{* * *}$ & $0.7805^{* * *}$ \\
\hline
\end{tabular}

Table 5: Results refer to equations 1 and 2. $\beta^{+}\left(\beta^{-}\right)$refers to upside (downside) volatility at time $t-1$. $\rho$ refers to hidden depth proportion at time $t-1$. Coefficients are calculated cross-sectionally. ${ }^{*}$ Significant at the $10 \%$ level, ${ }^{* *}$ Significant at the $5 \%$ level, $* * *$ Significant at the $1 \%$ level.

Unconditional frequencies of orders according to their aggressiveness level

\begin{tabular}{|c|c|c|}
\hline \hline Order Category & Usual Orders & Hidden Orders \\
\hline \hline BUY ORDERS & $\mathbf{1 0 0} \%$ & $\mathbf{1 0 0} \%$ \\
Large Orders & $4.5 \%$ & $3 \%$ \\
Market Orders & $5.5 \%$ & $10.5 \%$ \\
Small Orders & $25 \%$ & $3.5 \%$ \\
Orders within the spread & $15 \%$ & $25 \%$ \\
Orders at the best bid & $18 \%$ & $23 \%$ \\
Orders below the best quote & $32 \%$ & $35 \%$ \\
\hline SELL ORDERS & $\mathbf{1 0 0} \%$ & $\mathbf{1 0 0} \%$ \\
Large Orders & $5 \%$ & $3.5 \%$ \\
Market Orders & $5 \%$ & $11 \%$ \\
Small Orders & $28 \%$ & $4 \%$ \\
Orders within the spread & $15 \%$ & $25 \%$ \\
Orders at the best ask & $16 \%$ & $21 \%$ \\
Orders below the best quote & $31 \%$ & $35.5 \%$ \\
\hline \hline
\end{tabular}

Table 6: For both usual and hidden orders, we compute the unconditional probabilities of order types according to the aggressiveness level on both market sides. The order classification used is described in subsection 2.3. 
Depth behavior in the whole order book

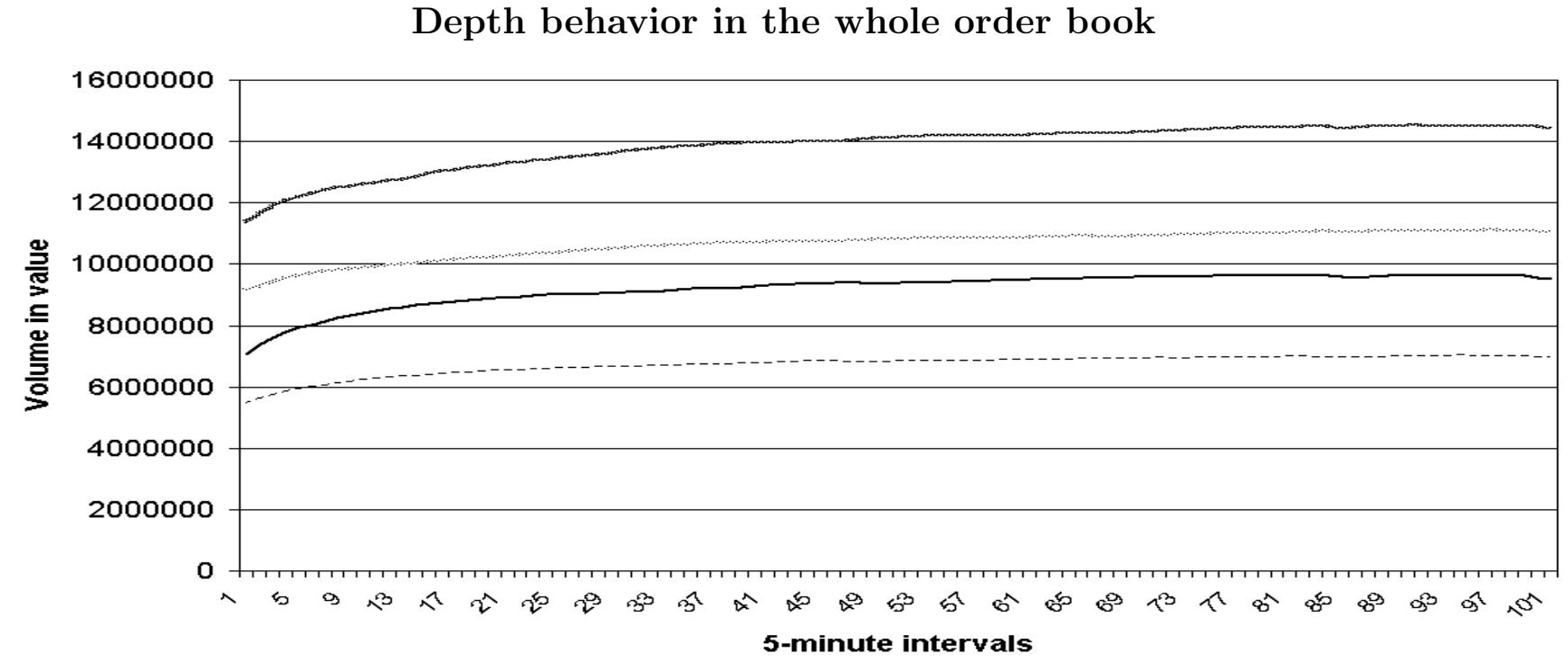

\begin{tabular}{|cc|}
\hline Total depth on the bid side & $\cdots \cdots . . .-$ Visible depth on the bid side \\
Total depth on the ask side & $\cdots-$ Visible depth on the ask side \\
\hline
\end{tabular}

Figure 1: Each continuous trading hour is partitioned into 5-minute intervals. We compute time weighted average volumes in value available in the whole order book across all CAC40 stocks and all days. Visible depth refers to disclosed quantities while total depth is measured by both hidden and displayed quantities. 
Depth behavior at the 5 best limits of the order book

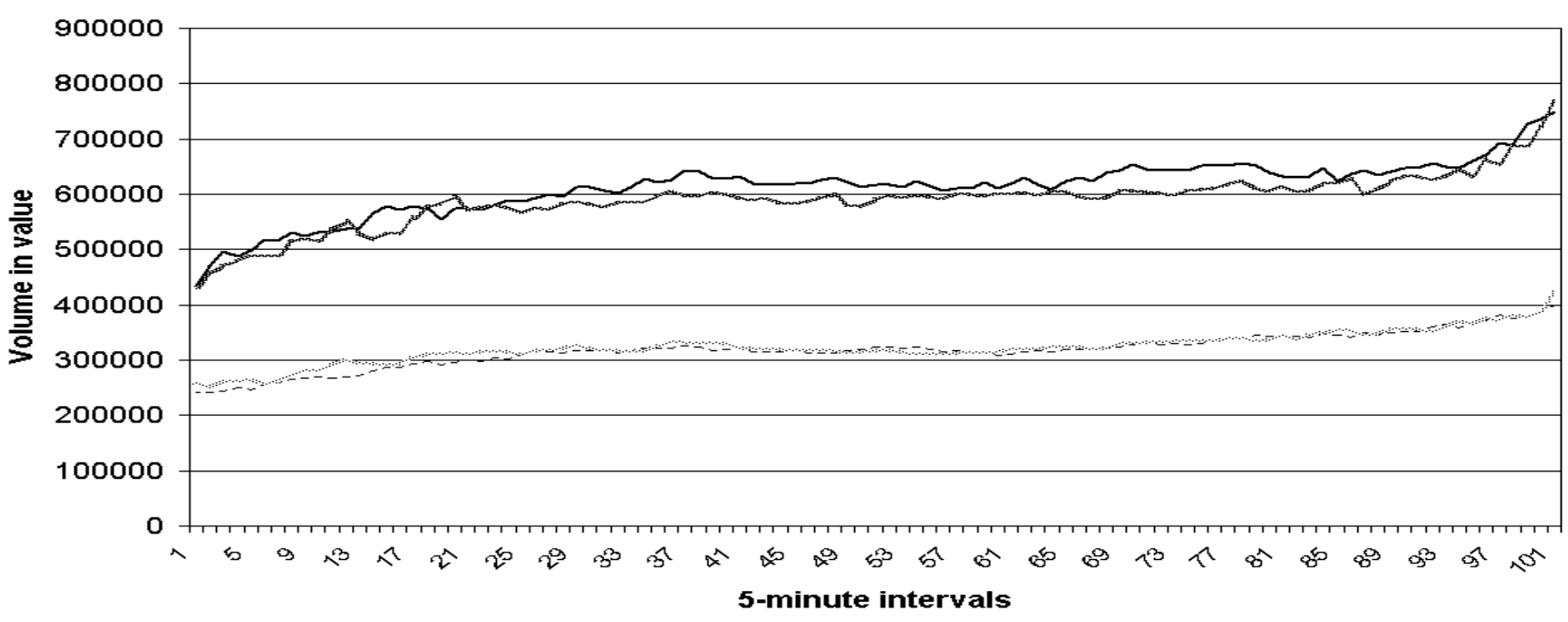

Total depth on the bid side

Total depth on the ask side $\quad . . . . . .$. Visible depth on the ask side

Figure 2: Each continuous trading hour is partitioned into 5-minute intervals. We compute time weighted average volumes in value available at the 5 best limits of the order book across all CAC40 stocks and all days. Visible depth refers to disclosed quantities while total depth is measured by both hidden and displayed quantities. 


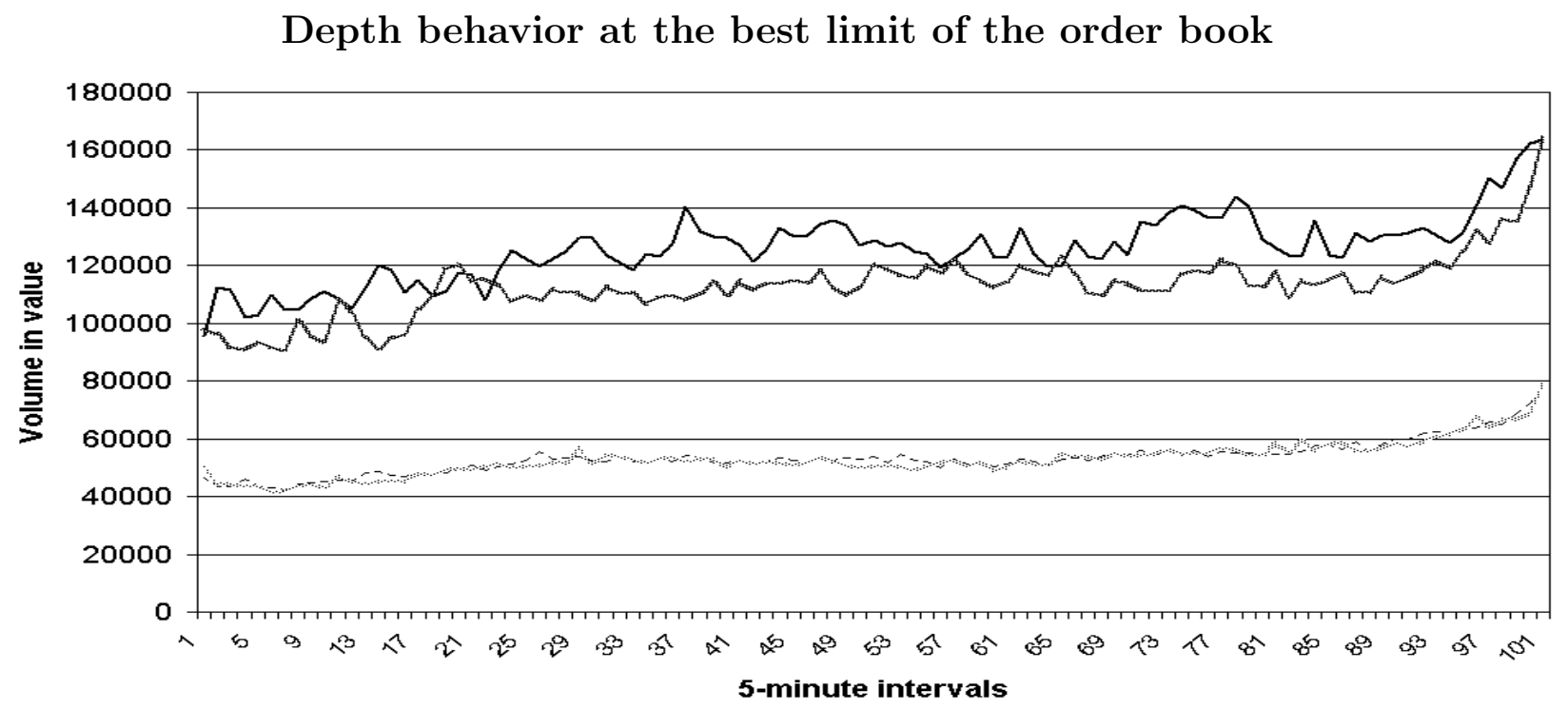

\begin{tabular}{|cc|}
\hline Total depth on the bid side & $\cdots \cdot . \cdot$ Visible depth on the bid side \\
\hline Total depth on the ask side & $\cdots$
\end{tabular}

Figure 3: Each continuous trading hour is partitioned into 5-minute intervals. We compute time weighted average volumes in value available at the best limit of the order book across all CAC40 stocks and all days. Visible depth refers to disclosed quantities while total depth is measured by both hidden and displayed quantities. 
Statistics about the difference between the price at the best limit and the order price

\begin{tabular}{|c|c|c|c|c|c|}
\hline \hline Tick Size & \# Orders & Mean Diff & Q3 Diff & Median Diff & Q1 Diff \\
\hline \hline \multirow{6}{*}{0.01} & 2805210 NHO & 43 & 16 & 6 & 2 \\
& & $(12)$ & $(15)$ & $(10)$ & $(7)$ \\
& \multirow{3}{*}{$132062 \mathrm{HO}$} & 23 & 20 & 9 & 4 \\
& & $(14)$ & $(18)$ & $(11)$ & $(8)$ \\
\hline 0.05 & $563113 \mathrm{NHO}$ & 16 & 9 & 3 & 1 \\
& & $(5)$ & $(6)$ & $(5)$ & $(4)$ \\
& $30431 \mathrm{HO}$ & 7 & 7 & 4 & 2 \\
& & $(6)$ & $(7)$ & $(5)$ & $(4)$ \\
\hline 0.1 & $261641 \mathrm{NHO}$ & 13 & 6 & 2 & 1 \\
& \multirow{3}{*}{$17786 \mathrm{HO}$} & $(5)$ & $(5)$ & $(4)$ & $(4)$ \\
& & 6 & 6 & 4 & 2 \\
& & $(5)$ & $(6)$ & $(5)$ & $(4)$ \\
\hline \hline
\end{tabular}

Table 7: For each order placed below the best quote, we compute the difference between the price at the best limit and the limit price of the order. The difference between the price at the best limit and the price at the fifth best limit is also calculted and is given in parentheses. Both differences are expressed in number of ticks. NHO (HO) refer to usual (hidden) orders. \# orders presents the number of orders. Mean Diff reports the average difference, Q3 Diff the upper quartile difference, Median Diff the median difference and Q1 Diff the lower quartile difference. 
Empirical frequencies of usual orders given the state of the order book

\begin{tabular}{|c|c|c|c|c|c|c|c|c|}
\hline & Buy & Buy within & Buy at & Buy below & Sell & Sell within & Sell at & Sell below \\
\hline Unconditional & $17 \%$ & $7 \%$ & $9 \%$ & $15 \%$ & $20 \%$ & $8 \%$ & $8 \%$ & $16 \%$ \\
\hline & \multicolumn{8}{|c|}{ LARGE Spread } \\
\hline Large spread & $12 \%$ & $12 \%$ & $9 \%$ & $16 \%$ & $14 \%$ & $13 \%$ & $8 \%$ & $16 \%$ \\
\hline Large DD Bid & $13 \%$ & $14 \%$ & $8 \%$ & $14 \%$ & $13 \%$ & $13 \%$ & $9 \%$ & $16 \%$ \\
\hline Small DD Bid & $11 \%$ & $10 \%$ & $10 \%$ & $17 \%$ & $15 \%$ & $13 \%$ & $8 \%$ & $16 \%$ \\
\hline Large DD Ask & $11 \%$ & $12 \%$ & $9 \%$ & $16 \%$ & $15 \%$ & $15 \%$ & $8 \%$ & $14 \%$ \\
\hline Small DD Ask & $12 \%$ & $12 \%$ & $9 \%$ & $16 \%$ & $13 \%$ & $11 \%$ & $9 \%$ & $18 \%$ \\
\hline Large HD Bid & $11 \%$ & $11 \%$ & $8 \%$ & $13 \%$ & $17 \%$ & $14 \%$ & $9 \%$ & $17 \%$ \\
\hline Small HD Bid & $12 \%$ & $13 \%$ & $9 \%$ & $16 \%$ & $13 \%$ & $13 \%$ & $8 \%$ & $16 \%$ \\
\hline Large HD Ask & $14 \%$ & $13 \%$ & $10 \%$ & $16 \%$ & $14 \%$ & $12 \%$ & $7 \%$ & $14 \%$ \\
\hline \multirow[t]{2}{*}{ Small HD Ask } & $11 \%$ & $12 \%$ & $9 \%$ & $15 \%$ & $14 \%$ & $13 \%$ & $9 \%$ & $17 \%$ \\
\hline & \multicolumn{8}{|c|}{ NARROW Spread } \\
\hline Narrow spread & $22 \%$ & $3 \%$ & $9 \%$ & $15 \%$ & $24 \%$ & $3 \%$ & $8 \%$ & $16 \%$ \\
\hline Large DD Bid & $25 \%$ & $4 \%$ & $8 \%$ & $14 \%$ & $22 \%$ & $3 \%$ & $8 \%$ & $16 \%$ \\
\hline Small DD Bid & $19 \%$ & $3 \%$ & $8 \%$ & $17 \%$ & $26 \%$ & $3 \%$ & $8 \%$ & $16 \%$ \\
\hline Large DD Ask & $20 \%$ & $3 \%$ & $9 \%$ & $15 \%$ & $27 \%$ & $4 \%$ & $8 \%$ & $14 \%$ \\
\hline Small DD Ask & $23 \%$ & $4 \%$ & $8 \%$ & $15 \%$ & $21 \%$ & $3 \%$ & $8 \%$ & $18 \%$ \\
\hline Large $H D$ Bid & $19 \%$ & $3 \%$ & $7 \%$ & $12 \%$ & $31 \%$ & $4 \%$ & $8 \%$ & $16 \%$ \\
\hline Small HD Bid & $22 \%$ & $3 \%$ & $9 \%$ & $17 \%$ & $22 \%$ & $3 \%$ & $8 \%$ & $16 \%$ \\
\hline Large HD Ask & $28 \%$ & $4 \%$ & $9 \%$ & $15 \%$ & $21 \%$ & $3 \%$ & $7 \%$ & $13 \%$ \\
\hline Small HD Ask & $19 \%$ & $4 \%$ & $8 \%$ & $15 \%$ & $25 \%$ & $4 \%$ & $8 \%$ & $17 \%$ \\
\hline
\end{tabular}

Table 8: This table reports the empirical frequency of usual order types conditional on the previous state of the order book. Each row is a probability vector adding up to $100 \%$ conditional on the order book state. The latter is characterized by the spread size and both displayed and hidden depths available at the best limit on each market side. For each stock, the spread (depth) is defined to be narrow (small) if it's smaller than its daily median. DD (HD) refers to the disclosed (hidden) depth. The unconditional probabilities of each order category are also provided. 
Empirical frequencies of hidden orders given the state of the order book

\begin{tabular}{|c|c|c|c|c|c|c|c|c|}
\hline & Buy & Buy within & Buy at & Buy below & Sell & Sell within & Sell at & Sell below \\
\hline Unconditional & $9 \%$ & $13 \%$ & $12 \%$ & $18 \%$ & $9 \%$ & $12 \%$ & $10 \%$ & $17 \%$ \\
\hline & \multicolumn{8}{|c|}{ LARGE Spread } \\
\hline Large spread & $4 \%$ & $19 \%$ & $11 \%$ & $17 \%$ & $5 \%$ & $18 \%$ & $10 \%$ & $16 \%$ \\
\hline Large DD Bid & $4 \%$ & $23 \%$ & $9 \%$ & $16 \%$ & $4 \%$ & $18 \%$ & $10 \%$ & $16 \%$ \\
\hline Small DD Bid & $4 \%$ & $16 \%$ & $14 \%$ & $18 \%$ & $5 \%$ & $18 \%$ & $10 \%$ & $15 \%$ \\
\hline Large DD Ask & $4 \%$ & $19 \%$ & $12 \%$ & $17 \%$ & $5 \%$ & $21 \%$ & $8 \%$ & $14 \%$ \\
\hline Small DD Ask & $5 \%$ & $19 \%$ & $11 \%$ & $17 \%$ & $4 \%$ & $15 \%$ & $12 \%$ & $17 \%$ \\
\hline Large HD Bid & $4 \%$ & $19 \%$ & $12 \%$ & $20 \%$ & $5 \%$ & $17 \%$ & $9 \%$ & $14 \%$ \\
\hline Small HD Bid & $4 \%$ & $19 \%$ & $11 \%$ & $16 \%$ & $5 \%$ & $19 \%$ & $10 \%$ & $16 \%$ \\
\hline Large HD Ask & $4 \%$ & $19 \%$ & $11 \%$ & $15 \%$ & $5 \%$ & $17 \%$ & $11 \%$ & $18 \%$ \\
\hline \multirow[t]{2}{*}{ Small HD Ask } & $4 \%$ & $19 \%$ & $11 \%$ & $18 \%$ & $5 \%$ & $18 \%$ & $10 \%$ & $15 \%$ \\
\hline & \multicolumn{8}{|c|}{ NARROW Spread } \\
\hline Narrow spread & $14 \%$ & $7 \%$ & $13 \%$ & $19 \%$ & $13 \%$ & $5 \%$ & $11 \%$ & $18 \%$ \\
\hline Large DD Bid & $15 \%$ & $8 \%$ & $11 \%$ & $18 \%$ & $12 \%$ & $6 \%$ & $11 \%$ & $19 \%$ \\
\hline Small DD Bid & $12 \%$ & $6 \%$ & $14 \%$ & $21 \%$ & $14 \%$ & $5 \%$ & $10 \%$ & $18 \%$ \\
\hline Large DD Ask & $13 \%$ & $7 \%$ & $13 \%$ & $20 \%$ & $14 \%$ & $6 \%$ & $10 \%$ & $17 \%$ \\
\hline Small DD Ask & $15 \%$ & $6 \%$ & $12 \%$ & $19 \%$ & $12 \%$ & $5 \%$ & $12 \%$ & $19 \%$ \\
\hline Large HD Bid & $14 \%$ & $6 \%$ & $14 \%$ & $21 \%$ & $14 \%$ & $6 \%$ & $10 \%$ & $15 \%$ \\
\hline Small HD Bid & $14 \%$ & $7 \%$ & $12 \%$ & $18 \%$ & $13 \%$ & $5 \%$ & $11 \%$ & $20 \%$ \\
\hline Large HD Ask & $15 \%$ & $7 \%$ & $13 \%$ & $16 \%$ & $13 \%$ & $5 \%$ & $11 \%$ & $20 \%$ \\
\hline Small HD Ask & $13 \%$ & $7 \%$ & $13 \%$ & $20 \%$ & $14 \%$ & $6 \%$ & $10 \%$ & $17 \%$ \\
\hline
\end{tabular}

Table 9: This table reports the empirical frequency of hidden order types conditional on the previous state of the order book. Each row is a probability vector adding up to $100 \%$ conditional on the order book state. The latter is characterized by the spread size and both displayed and hidden depths available at the best limit on each market side. For each stock, the spread (depth) is defined to be narrow (small) if it's smaller than its daily median. DD (HD) refers to the disclosed (hidden) depth. The unconditional probabilities of each order category are also provided. 
Empirical frequencies of usual orders given the last usual order

\begin{tabular}{|c|c|c|c|c|c|c|c|c|c|c|c|c|}
\hline \hline \multirow{2}{*}{ Order t-1 } & \multicolumn{10}{|c|}{ Order t } \\
\cline { 2 - 11 } & 1 & 2 & 3 & 4 & 5 & 6 & 7 & 8 & 9 & 10 & 11 & 12 \\
\hline 1 & $\mathbf{1 2}$ & 5 & 17 & 9 & 6 & 11 & 1 & 1 & 7 & 4 & 7 & 20 \\
2 & 5 & $\mathbf{1 2}$ & 17 & 5 & 7 & 12 & 1 & 2 & 8 & 3 & 11 & 17 \\
3 & 4 & 4 & $\mathbf{2 9}$ & 7 & 8 & 12 & 1 & 2 & 9 & 3 & 7 & 14 \\
4 & 2 & 2 & 12 & $\mathbf{1 9}$ & 9 & 15 & 1 & 1 & 7 & 12 & 7 & 13 \\
5 & 2 & 3 & 13 & 8 & $\mathbf{1 5}$ & 17 & 2 & 2 & 11 & 6 & 8 & 13 \\
6 & 2 & 2 & 10 & 7 & 9 & $\mathbf{2 6}$ & 2 & 2 & 11 & 7 & 7 & 15 \\
& & & & & & & & & & & & \\
7 & 1 & 1 & 6 & 3 & 7 & 20 & $\mathbf{1 4}$ & 5 & 19 & 8 & 5 & 11 \\
8 & 1 & 2 & 7 & 3 & 12 & 16 & 6 & $\mathbf{1 1}$ & 18 & 5 & 7 & 12 \\
9 & 1 & 2 & 8 & 3 & 7 & 13 & 4 & 4 & $\mathbf{3 2}$ & 7 & 7 & 12 \\
10 & 1 & 1 & 6 & 11 & 7 & 13 & 2 & 2 & 14 & $\mathbf{2 0}$ & 8 & 15 \\
11 & 1 & 3 & 10 & 5 & 9 & 13 & 2 & 3 & 15 & 8 & $\mathbf{1 4}$ & 17 \\
12 & 2 & 2 & 10 & 6 & 8 & 14 & 2 & 2 & 13 & 7 & 8 & $\mathbf{2 6}$ \\
\hline \hline
\end{tabular}

Table 10: This table exhibits the empirical frequency of each of the twelve order categories conditional on the previous usual order. Each row (column) refers to a given order at time t-1 (t). Each row represents a probability vector adding up to $100 \%$. We get these empirical probabilities after pooling all stocks. Category 1 (7) refers to large buy (sell) orders. Category 2 (8) refers to market buy (sell) orders. Category 3 (9) refers to small buy (sell) orders. Category 4 (10) refers to buy (sell) orders within the spread. Category 5 (11) refers to buy (sell) orders at the best bid (ask). Category 6 (12) refers to buy (sell) orders below the best bid (ask).

Empirical frequencies of hidden orders given the last hidden order

\begin{tabular}{|c|c|c|c|c|c|c|c|c|c|c|c|c|}
\hline \hline \multirow{2}{*}{ Order t-1 } & \multicolumn{10}{|c|}{ Order t } \\
\cline { 2 - 11 } & 1 & 2 & 3 & 4 & 5 & 6 & 7 & 8 & 9 & 10 & 11 & 12 \\
\hline 1 & $\mathbf{9}$ & 6 & 3 & 8 & 9 & 16 & 1 & 5 & 1 & 4 & 4 & 34 \\
2 & 3 & $\mathbf{1 5}$ & 3 & 8 & 12 & 19 & 1 & 6 & 1 & 4 & 10 & 18 \\
3 & 4 & 7 & $\mathbf{2 1}$ & 3 & 15 & 10 & 1 & 4 & 1 & 1 & 7 & 26 \\
4 & 2 & 4 & 1 & $\mathbf{2 3}$ & 11 & 20 & 1 & 3 & 1 & 14 & 7 & 13 \\
5 & 2 & 5 & 2 & 13 & $\mathbf{1 7}$ & 23 & 1 & 5 & 1 & 10 & 8 & 13 \\
6 & 1 & 4 & 2 & 10 & 9 & $\mathbf{4 2}$ & 2 & 3 & 2 & 8 & 6 & 11 \\
& & & & & & & & & & & & \\
7 & 1 & 5 & 1 & 6 & 7 & 13 & $\mathbf{7}$ & 8 & 7 & 9 & 12 & 24 \\
8 & 1 & 6 & 1 & 5 & 11 & 17 & 3 & $\mathbf{1 6}$ & 4 & 6 & 9 & 21 \\
9 & 1 & 3 & 1 & 2 & 5 & 7 & 2 & 7 & $\mathbf{4 1}$ & 5 & 12 & 14 \\
10 & 2 & 3 & 1 & 15 & 10 & 15 & 1 & 3 & 1 & $\mathbf{1 7}$ & 10 & 22 \\
11 & 1 & 4 & 1 & 11 & 9 & 13 & 1 & 5 & 3 & 13 & $\mathbf{1 5}$ & 24 \\
12 & 1 & 3 & 1 & 9 & 7 & 12 & 1 & 3 & 1 & 8 & 8 & $\mathbf{4 6}$ \\
\hline \hline
\end{tabular}

Table 11: This table exhibits the empirical frequency of each of the twelve order categories conditional on the previous hidden order. Each row (column) refers to a given order at time t-1 (t). Each row represents a probability vector adding up to $100 \%$. We get these empirical probabilities after pooling all stocks. Category 1 (7) refers to large buy (sell) orders. Category 2 (8) refers to market buy (sell) orders. Category 3 (9) refers to small buy (sell) orders. Category 4 (10) refers to buy (sell) orders within the spread. Category 5 (11) refers to buy (sell) orders at the best bid (ask). Category 6 (12) refers to buy (sell) orders below the best bid (ask). 


\section{Average proportions of split orders}

\begin{tabular}{|c|c|c|}
\hline \hline Category & Usual orders & Hidden orders \\
\hline \multirow{3}{*}{$1-1$} & \multicolumn{2}{|c|}{ Bid side } \\
\cline { 2 - 3 } $2-2$ & 44 & 96 \\
$3-3$ & 39 & 56 \\
$4-4$ & 39 & 98 \\
$5-5$ & 30 & 31 \\
$6-6$ & 34 & 48 \\
& 42 & 71 \\
$7-7$ & 46 & 90 \\
$8-8$ & 41 & 66 \\
$9-9$ & 41 & 94 \\
$10-10$ & 30 & 25 \\
$11-11$ & 37 & 41 \\
$12-12$ & 42 & 75 \\
\hline \hline
\end{tabular}

Table 12: This table reports, for both usual and hidden orders, the global average proportions (expressed in \%) of split orders. Categories 1 and 7 refer to 'large orders', categories 2 and 5 refer to 'market orders', categories 3 and 9 refer to 'small orders', categories 4 and 10 refer to 'orders within the spread', categories 5 and 11 refer to 'orders at the best quote' and categories 6 and 12 refer to 'orders below the best quote'. 